\title{
CORRESPONDENCE
}

\section{Not so civil}

SIR - Your comments (Nature 292, 396; 1981, and 287,$264 ; 1980$ ) on the recent Review of the Scientific Civil Service (1980) do not mention a major impediment discouraging scientists in the civil service from moving to administrative work. This is the opportunity post system. Open opportunity posts may be filled by suitable staff from any group or class in the service, and an increase in the number of such posts is recommended in the Review. However, on appointment to an opportunity post the successful candidate is paid the salary appropriate to his class of origin. In other words there are several rates for the same job. This is obviously unjust. It discriminates against scientists because in the civil service members of the administrative class are paid much more than their equivalents in scientific grades. For example the first secretary (science and technology) in the Paris embassy (an opportunity post at principal "level") may be paid over $£ 1,400$ p.a. extra if he happens to be from the administrative rather than the scientific class.

If different salaries were paid for a particular post according to the sex or colour of the incumbent it would be illegal. An equally artificial form of discrimination against scientists moving to administrative work in the civil service is likely to ensure that such moves continue to be few.

C.E. Dyte

Datchet, Slough, UK

\section{Risk of radon}

SIR - R.D. Evans et al. (Nature 12 March, p.98) considered the individual lung cancer risk to the general population from indoor exposure to radon-222 and concluded that a current upper estimate is $10^{-4}$ per lifetime per working level month. The authorship was remarkable in consisting of six widely recognized senior experts from four countries, and the estimate made was equally noteworthy - an agreement on a risk that was reasoned from cited data that vary over a factor of nearly 50 .

It is encouraging that experts can agree, but it is also potentially intimidating. For this reason it is vital to recognize the extent of the continuing uncertainty, and regard the recent estimate only as a starting point rather than a known value. Any number that is selected from within a possible range of 50 times can scarcely be regarded as an upper limit.

Although Evans et al. described many of the uncertainties in their estimate, a further potentially major consideration was not included. The general background effect of radon was assessed by identifying lung cancer rates before cigarette smoking became popular. Those rates are, however, not relevant if smoking increases the risk more than additively in a population where most people are exposed to tobacco smoke. Such would be the case if tobacco smoke is a promoter - an agent which accelerates the development of lung cancer but does not of itself nucleate cancer. Data from studies on rats ${ }^{1}$ in fact show such an effect - increased lung cancer from exposure to both smoke and radon but no lung cancer from smoke alone. And human data from uranium miners ${ }^{2}$ have shown a similar enhancement from both smoking and radon. No hunian data are available where radon is totally absent. Our two references are by no means conclusive, but they make it evident that there is a significant possibility that the appropriate background level of radon-related lung cancer is considerably higher than the value assumed by Evans et al.

\section{General Electric Research \&}

Robert L. Fleischer

Development Center, New York, USA

1. Chameaud, J., Perraud, R., Chretien, J., Massen, R. \& Lafuma, J. Symp. Late Biological Effects of Ionizing Radiation, 429-436 (IAEA, Vienna, 1978)

2. Lundin, F.E. Jr, Lloyd, J.W., Smith, E.M., Archer, V.E. \& Holaday, D.A. Hith Phys. 16, 571-578 (1969)

SIR - There is some uncertainty, of course, in our estimate of risk, but there is more uncertainty in the proposition that it may be considerably higher.

Authors have put forward various estimates of the risk coefficient for lung cancer in uranium miners, but a value in the range $1-5 \times 10^{-4}$ per working level month commands widest support. It derives from miners who smoked. We argued that a rounded value of $10^{-4}$ per working level month would be an appropriate upper bound for exposure to radon decay products in the home.

Such a value is seen to account for virtually all the lung cancers in a general population with relatively little smoking. Although one cannot separate the numerical influence of radiation and cigarettes, we are encouraged by the epidemiological circumstances and dosimetric considerations to believe that we are not seriously underestimating the risk.

M.C. O.'Riordan

National Radiological Protection Board, Oxon, UK

DR O'RIORDAN, a colleague of the late Dr A.S. Maclean, has replied on behalf of Evans et al.

\section{Antibiotic practice}

SIR - The arguments in your leading article "Saving antibiotics from themselves" (Nature 20 August, p.661) are very persuasive. However, in general practice at least the fears of widespread antibiotic resistance have not been realized. In more than thirty years of clinical experience in general practice of both myself and my colleagues, no loss of antibiotic efficacy has been observed. This is not to say that antibiotic resistance is not a problem in the hospital environment.

Antibiotic resistance may be advantageous to the organism in the host but when present in the general environment it might be selected against by measures not yet understood.

Most physicians would agree that a tenfold reduction in the prescribing of antibiotics would probably have negligible effect on the health of patients in advanced countries. However, such a reduction would encounter considerable resistance from the patients themselves and impose delays in the commencement of treatment when it is genuinely required, and additional burdens on bacteriological departments.

Before such measures are undertaken it would be wise to ensure that the theoretical dangers of antibiotic resistance are in fact realized in practice and that organisms possessing antibiotic resistance are not at some kind of disadvantage when circulating in the general environment which keeps their numbers down to a level at which their dangers remain insignificant.

Marlow, Bucks, UK

BRENNICi JANES

\section{Fully blind review}

SIR - To make the present review system a valuable screening procedure it is necessary that the authors be anonymous just as the referees are. I agree with Dr Gaylarde (Nature 30 July, p.402) that the pages containing the author's name, address and also the acknowledgements should be retained in the editorial office when a manuscript is forwarded to referees. However, I am afraid that a referee can still know the names and addresses of the authors if the authors choose to quote their own work in the first person, for example, as follows: "We have previously shown (Jones et al. 1980) that . . ." To ensure double-blind evaluation of a given piece of work, I suggest that the authors quote even their own work in the third person, that is, as follows: "Jones et al. have previously shown (1980) that . . ." After double-blind evaluation of a manuscript, the authors and the referees, if desired, can be made known to each other.

Department of Immunology and

B. SESHI

Microbiology,

Wayne State University School of Medicine, Detroit, Michigan, USA

\section{Tamuz bombing}

SIR - Your editorial on Isracli bombing was sanctimonious and unrealistic (Nature 18 June, p.523). Don't you realize that Israel and Iraq are at war? That Iraq refused to sign a peace agreement?

The only reason Iraq is not bombing Israel now, or ever since the 1967 war, is because Iraq cannot do it - its planes will be destroyed by Israel. So instead, Iraq sends armaments and soldiers to the Palestinians in Lebanon to fight the Israelis. The Iraqis themselves picked an easier target in Iran, or so it seemed at the beginning of their war.

You can't understand what it means to be at war with a country? How the Israelis have to fight enemies in Lebanon, Libya, Iraq, Syria, Jordan? You don't understand what this means?

The headlines in tonight's newspaper, 24 June 1981, read "Iraq's Hussein demands Arabs be given A-bomb". Iraq was building an A-bomb for all the Arabs, not only itself. "If you are looking for evidence, this is it." "The only thing the Iraqis want is an atomic bomb to use against Israel."

Also in Chem. Eng. News of 15 June, "The Iraqi reactor could have produced enough plutonium each year for about one bomb",

The "Non-Proliferation Treaty" is a farce. Countries at war do not observe such niceties. As I stated: your cditorial is sanctimonious making a pretence of righteousness and reality. Your readers should expect better from a science periodical.

A.B. Caripnter

Stoller Research Co.,

Santa Cruz, California, USA 